\begin{tabular}{ccc} 
Contents available at: Sri Lanka Journals Online & Tropical Agricultural Research \\
Journal Home Page: https://tar.sljol.info & \\
\hline
\end{tabular}

\title{
Effect of In-vitro Gastrointestinal Digestion and Dialysis Process on Phenolic Compounds and Antioxidant Capacity of Selected Underutilized Fruits in Sri Lanka
}

\author{
H.A.C.O. Hettiarachchi*, K.D.P.P. Gunathilake and S. Jayatilake \\ Department of Food Science \& Technology, Faculty of Livestock, Fisheries \& Nutrition, Wayamba University of Sri Lanka, \\ Makandura, Gonawila, Sri Lanka.
}

\section{ARTICLE INFO}

\section{Article history:}

Received: 31 July 2020

Revised version received: 13 October 2020

Accepted: 26 October 2020

Available online: 1 April 2021

\section{Keywords:}

Annona muricata

Annona squamosa

Gastrointestinal digestion

Elaeocarpus serratus

Pouteria campechiana

\section{Citation:}

Hettiarachchi, H.A.C.O., Gunathilake, K.D.P.P. and Jayatilake, S. (2021). Effect of In-vitro Gastrointestinal Digestion and Dialysis Process on Phenolic Compounds and Antioxidant Capacity of Selected Underutilized Fruits in Sri Lanka. Tropical Agricultural Research, 32(2): 212-218.

DOI: http://doi.org/10.4038/tar.v32i2.8468

Hettiarachchi, H.A.C.O.

https://orcid.org/0000-0003-3598-8613

\section{ABSTRACT}

The stability of phytochemicals and their inherent bioactivity may change after being subjected to gastro-intestinal digestion. This study investigated the bioactive potential of Elaeocarpus serratus, Pouteria campechiana, Annona squamosa and Annona muricata in terms of polyphenolic content and the antioxidant capacity. The in-vitro digestion process was carried out to quantify bioaccessible and bioavailable phytochemicals through each digestion phase analyzed by Folin-Ciocalteu method, DPPH radical scavenging assay and the total antioxidant capacity (TAC) of fruit extracts. The total phenolic contents (TPC) of the methanolic extracts of $A$. squamosa, E. serratus, $A$. muricata and P. campechiana were $718,525,370$ and $306 \mu$ gallic acid equivalents per $\mathrm{g}$ fresh weight ( $\mu \mathrm{g}$ GAE per $\mathrm{g} \mathrm{FW}$ ), respectively. The highest absorption of phenolic compounds during the digestion was observed for P. campechiana as indicated by the TPC of the dialysis phase of extract (44.90 $\mu \mathrm{g}$ GAE per g FW) when compared with the initial TPC of fresh methanolic extract, which was the lowest of the fruits tested. The DPPH radical scavenging activity of fresh methanolic extracts of E. serratus (95.3\%), A. squamosa (95.2\%) and A. muricata (94.0\%) showed a significantly higher percentage than P. campechiana (37.2\%). The TPC, DPPH radical scavenging and TAC in the extracts of all digestion phases were lower, compared to their fresh methanolic extracts and may be attributed to the partial release or degradation of phenolic compounds during the digestion.

*Corresponding author: osh0626@gmail.com 


\section{INTRODUCTION}

The significance of underutilized crop species in contributing to world food and nutrition security has received substantial coverage by scientists in recent years. These crops belonging to categories such as cereals, legumes, vegetables, oilseeds, roots and tubers, aromatic and medicinal plants, fruits and nuts, have earned collective names such as 'neglected and underutilized' crops (Padulosi et al., 2011). According to Ravi et al. (2010), these crops have traditionally been under cultivation and intrinsically linked with livelihood and cultural identity of local tribal communities. They are very much recognized for their rich nutritious profile with high bioavailable minerals, vitamins, dietary fibre, and other phytochemicals. Owing to the phytochemical profile, fruit, bark, leaves, stem, root, twig and sap of many fruit and vegetable crops have been used as ingredients in traditional medicine in early civilizations to treat many health complications (Khoo et al., 2016). Elaeocarpus serratus (Ceylon Olive), Pouteria campechiana (Lawulu), Annona squamosa (WeliAatha-Custard Apple) and Annona muricata (Katu AnodaSoursop) are underutilized fruit crops, rich in phytochemicals because of which both are considered having good antioxidant properties to fight many oxidative stress-related chronic diseases.

Sugar apple (a.k.a. Custard apple) has been reported to possess analgesic, anti-inflammatory, antipyretic, antiulcer, and antiseptic and abortifacient activities (Chavan et al., 2010). As reported by Coria-Téllez et al. (2018) Soursop has exhibited a high potential to be used as natural medicine for arthritic pain, neuralgia, arthritis, diarrhoea, dysentery, fever, malaria, parasites, rheumatism, skin rashes and worms, and also been eaten to elevate breast milk after childbirth. Canistel has been reported to possess many biologically active polyphenolic antioxidants including gallic acid, (+)-gallocatechin, (+)catechin, $(-)$-epicatechin, dihydromyricetin, $(+)$ cate-chin-3-O-gallate and myricitrin (Aseervatham et al., 2014). As reported by Das et al. (2017) Ceylon Olive (Elaeocarpus serratus) is used in folk medicine to treat stress, anxiety, depression, palpitation, nerve pain, epilepsy, migraine, lack of concentration, asthma, hypertension, arthritis and liver diseases. Hence some of the recent trends in food and nutrition research are to identify antioxidant rich dietary sources, separation and purification of bioactive compounds and development of functional food products and preparation of nutraceuticals which may act as supplements of such healthy properties. Even though, there are many logical and theoretical advantages of food-based approach for disease prevention, studies of specific foods have been limited by the variation in bioactive content and incomplete chemical characterization (Gu et al., 2013). Therefore, these crops have to be chemically characterized and the purified compounds have to be highly desirable, easily incorporated into a diet / product which is stable over time and storage conditions. However, bioavailability, bioaccessibility and metabolic fate of bioactives are the major influencing factors of the beneficial effects of phytochemicals present in fruits and vegetables (Tagliazucchi et al., 2010). The availability of phytochemicals in consumed fruits for metabolism after digestion and absorption through the human gastrointestinal tract may directly affect the beneficial effects they deliver. The bioactivity of those compounds may subject to change with the instability and the partial release of the compound from the food matrix. Hence, the bioaccessibility and bioavailability of phytochemicals should be examined to discover the efficacy of fresh fruits or fruit-based value-added products.

Many bioactive compound profiles have been detected using chemically extracted samples, mainly using methanol-water mixtures. Under in vivo conditions, polyphenols from the diet have to be extracted following gastrointestinal (GI) digestion. The nature of extractable phytochemicals, their stability and their antioxidant activity depend on many factors such as food matrix, $\mathrm{pH}$, temperature, the presence of inhibitors or enhancers of absorption, the presence of enzymes, host, and other related factors (Bouayed et al., 2011). Although the GI tract is good at extracting phytochemicals, only a part of the phytochemicals is extracted and becomes available for intestinal uptake during digestion. Therefore, in vitro GI models have been developed for assessing bioaccessibility, allowing the study of changes in dietary components during the gastric and the intestinal stage. Recent studies of in vitro digestion process on phenolic compounds of soursop have reported that the highest release of phenolic compounds had occurred during intestinal stage and phenolic compound bioaccessibility was 83.9\% for soursop, in which gallic, caffeic and chlorogenic acids were mainly detected (BlancasBenítez et al., 2019).

This study was carried out using the in-vitro human digestion model in five phases: pre-digestion, oral digestion, gastric digestion, dialysis and gastrointestinal digestion to quantify the amount of bioaccessible and bioavailable phenolics and their antioxidant capacity through each digestion phase. 
This model also reveals the polyphenol fraction for further uptake after digestion, following dialysis through a semipermeable cellulose membrane. The concentrations of phenolic constituents in these fractions were then compared with that of extracts prepared from freeze dried powder by chemical extraction using methanol.

\section{MATERIALS AND METHODS}

\section{Materials}

Gallic acid, ascorbic acid, 2,2-diphenyl-1picrylhydrazyl (DPPH), bile salts (mixture of sodium cholate and sodium deoxycholate), pepsin from porcine gastric mucosa, pancreatin from pig pancreas, Folin-Ciocalteu's reagent, methanol and dialysis tubing cellulose membranes were obtained from Sigma-Aldrich, St. Louis, MO, USA through Analytical Instrument Pvt Ltd, Colombo, Sri Lanka. All chemicals used in this study were of analytical grade.

\section{Sample preparation}

Elaeocarpus serratus (Ceylon Olive), Pouteria campechiana (Lawulu), Annona squamosa (Weli Aatha-Custard Apple) and Annona muricata (Katu Anoda-Soursop) were collected at correct maturity stage (more than $75 \%$ of the fruit flesh is soft and having pale olive greenish peel with slight yellow touch) from local home gardens at Kurunegala and Gampaha areas of Sri Lanka. Fruits were washed, peeled and seeds were removed to obtain the flesh part for freeze drying.

\section{Preparation of methanolic extract}

Fleshy part of the fruits was freeze dried (Martin Christ, Freeze dryer, Alpha 1-2/LD) for 24 h. A weight of freeze dried sample equivalent to $10 \mathrm{~g}$ of fresh weight from fruit samples was mixed with 70 $\mathrm{mL}$ methanol/water $(80 \%, \mathrm{v} / \mathrm{v})$ and vortexed at high speed for $5 \mathrm{~min}$ and centrifuged (Hettich, EBA 20 ) at $2100 \mathrm{~g}$ for $10 \mathrm{~min}$. The extracts were filtered through a Whatman No. 42 filter paper and the prepared extracts were stored at $-18^{\circ} \mathrm{C}$.

\section{In-vitro gastrointestinal digestion}

Fresh fruit samples were subjected to gastrointestinal digestion following the method published by Gunathilake et al. (2018) and Wang et al. (2020) with modifications. Fleshy parts (10 g of each fruit flesh) of four fruits were separately added to $10 \mathrm{~mL}$ fresh saliva donated by a healthy adult. The mixtures were ground using mortar and pestle for $1 \mathrm{~min}$ to imitate chewing. They were incubated at $37^{\circ} \mathrm{C}$ for $10 \mathrm{~min}$. Exactly $5 \mathrm{~mL}$ of each sample was collected and diluted with $0.9 \% \mathrm{NaCl}$ followed by filtration through Whatman No. 42 filter paper and filtered aliquots were stored in amber colour bottles for further analysis. The $\mathrm{pH}$ of admixture was adjusted to 2.0 using $6.0 \mathrm{~mol} / \mathrm{L}$ of $\mathrm{HCl}$ solution to inactivate salivary amylase.

Then $50 \mathrm{~mL} 0.9 \% \mathrm{NaCl}$ and $4.0 \mathrm{~mL}$ pepsin solution $940 \mathrm{mg} / \mathrm{mL}$ in $0.1 \mathrm{M} \mathrm{HCl}$ were added to the sample maintaining the $\mathrm{pH}$ at 2.0. The mixture was incubated for $1 \mathrm{~h}$ in a LabTech shaking water bath (DAIHAN LABTECH, Korea) at $37{ }^{\circ} \mathrm{C}$ and $100 \mathrm{rpm}$. After gastric digestion, $5 \mathrm{~mL}$ aliquots of each sample were collected, diluted and filtered through Whatman No. 42 filter paper and stored for further analysis.

Segments of dialysis tubing cellulose membrane (average flat width; $33 \mathrm{~mm}$, MWCO 12,000 Da) were cut into a specified length $(15.0 \mathrm{~cm})$, rinsed both outer and inner surfaces with $0.9 \% \mathrm{NaCl}$ solution before starting the intestinal digestion phase with dialysis. Prepared dialysis bags were filled with $5.5 \mathrm{~mL} \mathrm{NaCl}(0.9 \%)$ and $5.5 \mathrm{~mL} \mathrm{NaHCO}_{3}$ $(0.5 \mathrm{M})$. Then the open end was sealed with clips and immersed into gastric digestion mixture immediately after digestion. The mixtures were incubated at $37^{\circ} \mathrm{C}$ and $100 \mathrm{rpm}$ for $45 \mathrm{~min}$ in a shaking water bath. Before adding pancreatin-bile mixture consisting $2 \mathrm{mg} / \mathrm{mL}$ pancreatin and 12 $\mathrm{mg} / \mathrm{mL}$ bile extract dissolved in $0.1 \mathrm{M} \mathrm{NaHCO}_{3}$, to each digested mixture, the $\mathrm{pH}$ was brought to 6.5 with $\mathrm{NaHCO}_{3}$. After adding pancreatin-bile mixture, each digesta was incubated for $2 \mathrm{~h}$ at 37 ${ }^{\circ} \mathrm{C}$. Once the digestion is completed, $\mathrm{pH}$ of the mixtures was between 7-7.5. Aliquots were collected from the intestinal phase, filtered and stored for analysis as done previously. The dialysis bags were removed, washed with water and dried using paper cloth before measuring the weight of each. The content in the bags were transferred to measuring cylinders and diluted to a final volume of $14 \mathrm{~mL}$ with $0.9 \% \mathrm{NaCl}$ and then filtered through Whatman No. 42 filter papers and stored for further analysis.

All the aliquots thus collected were analyzed for their polyphenol content, antioxidant capacity and DPPH radical scavenging ability.

\section{Determination of DPPH radical scavenging ability}

The assay was conducted according to Hatano et al. (1988), to assess the capacity of prepared methanolic extracts and gastrointestinal digestion aliquots to scavenge the stable free radical DPPH. 
Freshly prepared methanolic solution of DPPH (1 $\mathrm{Mm}, 3.9 \mathrm{~mL}$ ) was added to $0.1 \mathrm{~m} \mathrm{~L}$ of sample and vortexed for 15 seconds before incubating at room temperature for $30 \mathrm{~min}$ in the dark. The absorbance was measured at $517 \mathrm{~nm}$ and the percentage scavenging ability was calculated using the following equation:

$$
\text { Scavenging ability } \%=\frac{(\mathrm{Ac}-\mathrm{As})}{\mathrm{Ac}} \times 100
$$

where, Ac and As are the absorbances of the control and the sample, respectively.

\section{Total phenolic content}

The total polyphenol content of methanolic extracts and gastrointestinal digestion aliquots were assessed using Folin-Ciocalteu's method of Singleton et al. (1999) with some modifications as described by Gunathilake et al. (2018). FolinCiocalteu's reagent $(0.5 \mathrm{~N}, 0.2 \mathrm{~mL})$ was added to 1 $\mathrm{mL}$ of the sample and incubated in the dark for 15 min. Then $5 \mathrm{~mL}$ of $\mathrm{Na}_{2} \mathrm{CO}_{3}(7.5 \%)$ were added to each mixture and incubated in the dark for $2 \mathrm{~h}$. The absorbance was measured using UV/VIS spectrophotometer and the concentration of total polyphenols was expressed as $\mu \mathrm{g}$ Gallic Acid Equivalents per $\mathrm{g}$ Fresh Weight of fruit flesh $(\mu \mathrm{g}$ GAE per g FW).

\section{Total antioxidant capacity}

The total antioxidant capacity of methanolic extracts and gastrointestinal digesta aliquots was analyzed according to the method described by Prieto et al. (1999). The antioxidant capacity was expressed as $\mu \mathrm{g}$ ascorbic acid equivalents per $g$ fresh weight of fruit flesh ( $\mu \mathrm{g}$ AAE per $g$ FW) using ascorbic acid standard curve.

\section{Statistical analysis}

ANOVA was conducted using the General linear model and significant differences among different crops and extracts were identified using the Tukey test in Minitab 18. Differences at $p<0.05$ were considered to be significant. All the data collected were presented as the mean \pm standard deviation for all assays where samples were analyzed in triplicate.

\section{RESULTS AND DISCUSSION}

The stability of phytochemicals and their inherent bioactivity may change after being subjected to gastrointestinal digestion. The bioaccessibility indicates the quantity of a compound released from its matrix in the gastrointestinal tract becoming available for absorption. The bioavailability shows the proportion which enters the circulation when introduced into the body and have an effect. Fresh methanolic extracts of fruit flesh samples analysed, represent the quantity of polyphenolic compounds available in food matrix. Aliquots collected from oral, gastric and gastrointestinal digestion phases carry phytochemical compounds released from the food matrix becoming available for absorption. Dialysis phase aliquot represents the bioavailable portion, absorbed through intestinal epithelium and which can be readily absorbed and entered to circulation. Antioxidants have to be bioaccessible in order to exert their bioactivity (Bouayed et al., 2011). According to Table 1, the total phenolic content (TPC) of methanolic extracts of E. serratus, P. campechiana, A. squamosa and A. muricata fresh fruitswas 525, 306, 718 and $370 \mu \mathrm{g}$ Gallic Acid Equivalent per g fresh weight ( $\mu \mathrm{g}$ GAE per g FW), respectively. The DPPH radical scavenging ability of methanolic extracts of $E$. serratus, $P$. campechiana, A. squamosa and A. muricata of fresh fruits was $95.2 \%, 37.2 \%, 95.2 \%$ and $94 \%$, respectively. Radical scavenging ability has a direct relationship with phenolic compound availability. The higher the amount of phenolic compounds the sample contains the higher the ability of radical scavenging. It may be due to low amount of phenolic compounds present in P. campechiana methanolic extract, the radical scavenging ability reported in much lower value (Table 1). A positive correlation may not always exist between the total phenolic content and DPPH radical scavenging activity. It may be due to other compounds that can act as electron donors to DPPH radical which is indicated as an antioxidant activity. The total antioxidant capacities (TAC) of E. serratus, $P$. campechiana, A. squamosa and A. muricata fresh methanolic extract were 147, 355, 90, $154 \mu \mathrm{g}$ ascorbic acid equivalent per $\mathrm{g}$ fresh weight $(\mu \mathrm{g} \mathrm{AAE}$ per g FW), respectively. During the oral phase digestion, even though phytochemical compounds in food matrix may not have undergone drastic $\mathrm{pH}$ changes or deterioration reactions unlike in gastric phase, all aliquots showed lower values for TPC, TAC and DPPH radical scavenging ability when compared with the TPC, TAC and DPPH radical scavenging ability values of their fresh methanolic extracts. Gastric phase aliquots of E. serratus, $P$. campechiana, A. squamosa and A. muricata reported a decrease in TAC $(30.80,26.80,13.77$, $49.05 \mu \mathrm{g}$ AAE per g FW, respectively) when compared with their fresh methanolic extracts. Due to high acidic $\mathrm{pH}$ of the gastric environment slight amount of degradation such as structural changes of the compound that will alter the bioactive 
Table 1: DPPH radical scavenging ability, Total Phenolic content and Total antioxidant capacity of selected underutilized fruit crops subjected to simulated in-vitro gastro-intestinal digestion and dialysis process

\begin{tabular}{|c|c|c|c|c|}
\hline $\begin{array}{l}\text { Scientific } \\
\text { name }\end{array}$ & Type of extract & $\begin{array}{l}\text { DPPH radical } \\
\text { Scavenging }{ }^{\dagger} \\
\text { Efficacy }(\%)\end{array}$ & 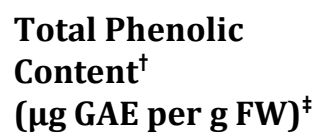 & $\begin{array}{l}\text { Total Antioxidant } \\
\text { Capacity }^{\dagger} \\
(\mu \mathrm{g} \text { AAE per g FW })^{\S}\end{array}$ \\
\hline \multirow[t]{5}{*}{ A. squamosa } & $\begin{array}{l}\text { Methanolic } \\
\text { extract }\end{array}$ & $95.25 \pm 0.09^{k}$ & $717.80 \pm 17.60^{\circ}$ & $90.10 \pm 6.02^{j}$ \\
\hline & Oral phase aliquot & $44.18 \pm 1.72^{\mathrm{g}}$ & $95.50 \pm 2.40^{j}$ & $78.02 \pm 1.42^{\mathrm{i}}$ \\
\hline & $\begin{array}{l}\text { Gastric phase } \\
\text { aliquot }\end{array}$ & $26.34 \pm 0.41 \mathrm{e}$ & $24.10 \pm 0.80^{\mathrm{b}}$ & $13.77 \pm 1.11^{\mathrm{a}}$ \\
\hline & $\begin{array}{l}\text { Dialysis phase } \\
\text { aliquot }\end{array}$ & $20.68 \pm 2.42^{\mathrm{d}}$ & $44.90 \pm 5.40^{\mathrm{e}}$ & $70.94 \pm 2.38^{h}$ \\
\hline & $\begin{array}{l}\text { Gastro-intestinal } \\
\text { phase aliquot }\end{array}$ & $8.02 \pm 0.68^{b}$ & $79.50 \pm 5.20^{\mathrm{i}}$ & $43.94 \pm 0.34^{\mathrm{e}}$ \\
\hline \multirow[t]{5}{*}{ A. muricata } & $\begin{array}{l}\text { Methanolic } \\
\text { extract }\end{array}$ & $93.99 \pm 0.73^{j}$ & $369.60 \pm 32.20^{\mathrm{m}}$ & $154.22 \pm 1.68^{\mathrm{m}}$ \\
\hline & Oral phase aliquot & $65.08 \pm 1.60^{h}$ & $77.20 \pm 0.60^{\mathrm{i}}$ & $34.85 \pm 1.76^{\mathrm{d}}$ \\
\hline & $\begin{array}{l}\text { Gastric phase } \\
\text { aliquot }\end{array}$ & $35.81 \pm 0.57 \mathrm{e}$ & $35.70 \pm 0.90^{\mathrm{d}}$ & $49.05 \pm 1.10^{\mathrm{f}}$ \\
\hline & $\begin{array}{l}\text { Dialysis phase } \\
\text { aliquot }\end{array}$ & $4.31 \pm 0.74^{\mathrm{a}}$ & $31.20 \pm 1.20^{c}$ & $26.91 \pm 1.67^{c}$ \\
\hline & $\begin{array}{l}\text { Gastro-intestinal } \\
\text { phase aliquot }\end{array}$ & $7.85 \pm 0.65^{b}$ & $74.60 \pm 1.50^{\mathrm{h}}$ & $29.52 \pm 2.71^{c}$ \\
\hline \multirow[t]{5}{*}{ E. serratus } & $\begin{array}{l}\text { Methanolic } \\
\text { extract }\end{array}$ & $95.25 \pm 0.31^{\mathrm{k}}$ & $524.98 \pm 5.58^{n}$ & $146.78 \pm 4.68^{\mathrm{l}}$ \\
\hline & Oral phase aliquot & $92.00 \pm 0.72^{\mathrm{i}}$ & $144.64 \pm 2.10^{\mathrm{k}}$ & $20.77 \pm 1.92^{\mathrm{b}}$ \\
\hline & $\begin{array}{l}\text { Gastric phase } \\
\text { aliquot }\end{array}$ & $61.78 \pm 10.72^{\mathrm{h}}$ & $53.79 \pm 0.70^{\mathrm{f}}$ & $30.80 \pm 1.17^{c}$ \\
\hline & $\begin{array}{l}\text { Dialysis phase } \\
\text { aliquot }\end{array}$ & $17.77 \pm 0.30^{c}$ & $11.62 \pm 1.19^{a}$ & $37.60 \pm 2.10^{\mathrm{d}}$ \\
\hline & $\begin{array}{l}\text { Gastro-intestinal } \\
\text { phase aliquot }\end{array}$ & $16.19 \pm 3.27^{c}$ & $47.05 \pm 2.64^{\mathrm{e}}$ & $64.08 \pm 0.38 \mathrm{~g}$ \\
\hline \multirow[t]{5}{*}{ P. campechiana } & $\begin{array}{l}\text { Methanolic } \\
\text { extract }\end{array}$ & $37.19 \pm 3.33^{f}$ & $306.14 \pm 17.59^{1}$ & $355.49 \pm 12.17^{n}$ \\
\hline & Oral phase aliquot & $33.25 \pm 2.30^{\mathrm{e}}$ & $59.99 \pm 0.82 \mathrm{~g}$ & $72.46 \pm 1.04^{h}$ \\
\hline & $\begin{array}{l}\text { Gastric phase } \\
\text { aliquot }\end{array}$ & $36.47 \pm 0.05^{f}$ & $48.60 \pm 0.75^{\mathrm{e}}$ & $26.80 \pm 1.74^{c}$ \\
\hline & $\begin{array}{l}\text { Dialysis phase } \\
\text { aliquot }\end{array}$ & $16.08 \pm 0.22^{\mathrm{c}}$ & $34.26 \pm 1.76^{\mathrm{d}}$ & $69.80 \pm 1.89^{h}$ \\
\hline & $\begin{array}{l}\text { Gastro-intestinal } \\
\text { phase aliquot }\end{array}$ & $5.21 \pm 0.99^{a}$ & $58.05 \pm 1.71^{g}$ & $47.60 \pm 1.46^{\mathrm{f}}$ \\
\hline
\end{tabular}

\footnotetext{
${ }^{\dagger}$ Means with different superscript letters in individual column are significantly $(\mathrm{p}<0.05)$ different from each other Values are presented as Mean $\pm S D, n=3$

${ }^{\ddagger} \mu \mathrm{g}$ Ascorbic acid equivalent per $\mathrm{g}$ fresh fruit weight (FW), and

$\S \mu \mathrm{g}$ Gallic acid equivalent per $\mathrm{g}$ fresh fruit weight (FW)
} 
properties initially attributed to the compound may occur. Since gastrointestinal tract is efficient in extracting phytochemicals as reported by Bouayed et al. (2011), the bioaccessible amount of polyphenolics may have contributed to the above TAC values. The TPC values reported for gastric phase aliquots of E. serratus, P. campechiana, A. squamosa and A. muricata $(53.8,48.6,24.1,35.7 \mu \mathrm{g}$ GAE per g FW, respectively) show a similar decreasing pattern, indicating the freely available phenolics released from food matrix. Even the DPPH radical scavenging activity of gastric phase aliquots of all the four samples were lower compared to their fresh methanolic extracts. However, the release of polyphenolic compounds into gastric phase was higher in P. campechiana when compared with E. serratus, A. squamosa and A. muricata. Gastrointestinal phase aliquots represent the remaining phenolic compounds from whatever the amount released from the food matrix and after undergoing the absorption process during the dialysis. Even though the TAC of gastrointestinal phase aliquot of $A$. squamosa (43.9 $\mu \mathrm{g}$ AAE per g FW) and P. campechiana (47.6 $\mu \mathrm{g} \mathrm{AAE}$ per $\mathrm{g}$ FW) were lower compared to TAC of their dialysis fractions (Table 1).

The TPC of gastrointestinal phase aliquot of $A$. squamosa (79.5 $\mu \mathrm{g}$ GAE per $\mathrm{g} \mathrm{FW}$ ) and $P$. campechiana (58.0 $\mu \mathrm{g}$ GAE per g FW) was higher than the TPC recorded for their dialysates. It may be due to having non-phenolic compounds that possess antioxidant activity which are more bioavailable than phenolic compounds. It is observed that the bioavailable phenolic compounds which are represented by the TPC of dialysis fractions, are lower in all four fruit types than their bioaccessible phenolic compounds (Table 2). Total phenolic contents in both dialysis fraction and gastro-intestinal aliquots may represent the total amount of bioacessible phenolics available in the food matrix.

As indicated in Table 2, the bioavailable or the potential uptake of phenolic compounds in tested fruits differ from each other. Tagliazucchi et al. (2010) reported that $62 \%$ of the originally present phenolics in grapes are bioaccessible. Furthermore, Tagliazucchi et al. (2010) have reported that radical scavenging activities of polyphenols may be $\mathrm{pH}$-dependent and greater scavenging capacity could be observed in the intestine than in stomach. However, the results obtained for DPPH scavenging ability of all four crops in gastric, dialysis and gastro-intestinal phase (Table 1) of this in-vitro model do not support the fact since gastric phase extracts have shown considerably higher scavenging activity.

Table 2: Bioavailable and bioaccessible phenolic compounds in selected underutilized fruit crops

\begin{tabular}{lrr}
\hline Fruit crop & $\begin{array}{r}\text { Bioaccessible } \\
\text { phenolic } \\
\text { compounds } \\
\text { (\%) }\end{array}$ & $\begin{array}{r}\text { Bioavailable } \\
\text { phenolic } \\
\text { compounds } \\
\text { (\%)(potential } \\
\text { uptake/dialysis) }\end{array}$ \\
\hline A. squamosa & 17.3 & 6.3 \\
A. muricata & 28.6 & 8.4 \\
E. serratus & 11.2 & 2.2 \\
P. campechiana & 30.2 & 11.2 \\
\hline
\end{tabular}

\section{CONCLUSION}

The TPC, DPPH radical scavenging percentage and TAC in the extracts of all digestion phases were lower when compared to their fresh methanolic extracts. It may be due to the partial release of bioactive compounds from food matrix to gastrointestinal juice and the instability of the compounds in a highly acidic gastric environment. The fraction of bioactive compounds absorbed by the small intestine is indicated by the dialysis phase extract. Even though P. campechiana fresh methanolic extract had lower TPC and DPPH radical inhibition percentage, it showed high amount of bioaccessible and bioavailable phenolics when compared with E. serratus, A. squamosa and A. muricata. It is proven with the percentage uptake of phenolics in dialysis phase extract of E. serratus, P. campechiana, A. squamosa and A. muricata with compared to their fresh methanolic extracts. However, it can be concluded that not all phytochemicals ingested exert the same beneficial effects owing to their inherent bioactive potential, but depending on their bioaccessiblity and bioavailability part of phytochemicals may have great benefits on human health. Further investigations should be carried out to obtain wellcorrelated results with human clinical studies.

\section{ACKNOWLEDGEMENT}

This work was supported by World Bank AHEAD project under the research grant AHEAD/RA3/DOR/WUSL/FST. 


\section{REFERENCES}

Aseervatham, G.S.B., Sivasudha, T., Sasikumar, J.M., Christabel, P.H., Jeyadevi, R. and Ananth, D.A. (2014). Antioxidant and hepatoprotective potential of Pouteria campechiana on acetaminophen-induced hepatic toxicity in rats. Journal of physiology and biochemistry. 70(1), $1-14$.

Blancas-Benítez, F.J., Montalvo-González, E., González-Aguilar, G.A. and Sáyago-Ayerdi, S.G. (2019). In vitro bioaccesibility and release kinetics of phenolic compounds from guava (Psidium guajava L.) and soursop (Annona muricata L.) pulp. TIP Revista Especializadaen Ciencias Químico-Biológicas. 22(1), 1-7

Bouayed, J., Hoffmann, L. and Bohn, T. (2011). Total phenolics, flavonoids, anthocyanins and antioxidant activity following simulated gastrointestinal digestion and dialysis of apple varieties: Bioaccessibility and potential uptake. Food chemistry. 128(1), 14-21.

Chavan, M.J., Wakte, P.S. and Shinde, D.B. (2010). Analgesic and anti-inflammatory activity of Caryophyllene oxide from Annona squamosa L. bark. Phytomedicine. 17(2), 149-151.

Coria-Téllez, A.V., Montalvo-Gónzalez, E., Yahia, E.M. and Obledo-Vázquez, E.N. (2018). Annona muricata: A comprehensive review on its traditional medicinal uses, phytochemicals, pharmacological activities, mechanisms of action and toxicity. Arabian Journal of Chemistry. 11(5), 662-691.

Das, P., Kar, P., Hasnu, S., Nath, S. and Tanti, B. (2017). Phytochemical screening and antioxidant activity of Elaeocarpus serratus L. of Assam. Journal of Pharmacognosy and Phytochemistry. 6(4). 866-869.

Gu, J., Ahn-Jarvis, J.H., Riedl, K.M., Schwartz, S.J., Clinton, S.K. and Vodovotz, Y. (2013). Characterization of black raspberry functional food products for cancer prevention human clinical trials. Journal of agricultural and food chemistry. 62(18), 3997-4006.

Gunathilake, K.D.P.P., Ranaweera, K.K.D.S. and Rupasinghe, H.P.V. (2018). Change of phenolics, carotenoids, and antioxidant capacity following simulated gastrointestinal digestion and dialysis of selected edible green leaves. Food chemistry. 245, 371-379.
Hatano, T., Edamatsu, R., Hiramatsu, M., Mori, A., Fujita, Y., Yasuhara, T., Yoshida, T. and Okuda, T. (1989). Effects of the interaction of tannins with co-existing substances. VI.: effects of tannins and related polyphenols on superoxide anion radical, and on 1, 1-Diphenyl-2-picrylhydrazyl radical. Chemical and Pharmaceutical Bulletin. 37(8), 2016-2021.

Khoo, H.E., Azlan, A., Kong, K.W. and Ismail, A. (2016). Phytochemicals and medicinal properties of indigenous tropical fruits with potential for commercial development. Evidence-Based Complementary and Alternative Medicine, 2016. Article ID 7591951, 20 pages. https://doi.org/10.1155/2016/ 7591951.

Padulosi, S., Heywood, V., Hunter, D. and Jarvis, A. (2011). Underutilized species and climate change: current status and outlook. pp. 507521. In: Yadav SS, Redden RJ, Hatfield JL, LotzeCampen H, Hall AE, eds. Crop Adaptation to Climate Change, Oxford, UK: Wiley-Blackwell.

Prieto, P., Pineda, M. and Aguilar, M. (1999). Spectrophotometric quantitation of antioxidant capacity through the formation of a phosphomolybdenum complex: specific application to the determination of vitamin E. Analytical Biochemistry. 269(2), 337-341.

Ravi, S.B., Hrideek, T.K., Kumar, A.K., Prabhakaran, T.R., Mal, B. and Padulosi, S. (2010). Mobilizing neglected and underutilized crops to strengthen food security and alleviate poverty in India. Indian Journal of Plant Genetic Resources. 23(1), 110-116.

Singleton, V.L., Orthofer, R. and Lamuela-Raventós, R.M. (1999). Analysis of total phenols and other oxidation substrates and antioxidants by means of folin-ciocalteu reagent. Methods in Enzymology, (Oxidants and Antioxidants, Part A); Academic Press: San Diego, CA, pp. 152-178

Tagliazucchi, D., Verzelloni, E., Bertolini, D. and Conte, A. (2010). In vitro bio-accessibility and antioxidant activity of grape polyphenols. Food Chemistry, 120(2), 599-606.

Wang, L., Zhou, P., Feng, R., Luo, Z., Li, X. and Gao, L. (2020). Anti-proliferation activities of Oryza sativa L. anthocyanins-Hohenbueheliaserotina polysaccharides complex after in vitro gastrointestinal digestion. Food and Chemical Toxicology. 135, p.111012. 